\title{
Synthesis of Alkoxybenzenes and Alkoxyvinylbenzenes and Their Chemosterilizing and Toxic Activity on Planococcus citri (Hom., Pseudococcidae)
}

\author{
I. Bélai, B. Darvas and G. Matolcsy \\ Research Institute for Plant Protection, Hungarian Academy \\ of Sciences, Budapest, P.O. Box 102, H-1525, Hungary
}

Received May 1, 1986

\begin{abstract}
Dialkoxy-, trialkoxy-, dialkoxyvinyl-, and trialkoxyvinylbenzenes were investigated for chemosterilant and toxic acitivity on Planococcus citri. The alkoxyvinylbenzenes were toxic; they reduced the egg production of the test insect. Dialkoxyvinylbenzenes decreased the number of eggs laid by females, but the chemosterilizing activity of the trialkoxy derivatives was not strong.

Larvae treated with $0.1 \%$ 1,5-diisopropoxy-4-vinylbenzene (6), 17\% survived. The surviving females were strongly retarded in their growth (which was $56 \%$ of normal) and their egg production was reduced by $70 \%$. Some of the small adults $(43 \%$ of the surviving females) failed to form an ovisac and did not lay eggs at all.
\end{abstract}

Ageratochromenes isolated from Ageratinae species ${ }^{1)}$ cause precocious metamorphosis in sensitive insect species, ${ }^{2)}$ and have been renamed "precocenes" (Table I: compounds 1 3). Precocenes also interfere with other physiological processes that involve juvenile hormones and can produce sterility in insects. Bowers et al. ${ }^{3)}$ observed that insects with telotrophic ovarioles, such as Dysdercus cingulatus, Oncopeltus fasciatus, Rhagoletis cerasi, and Epilancna varivestis, become sterile after precocene treatment. Similar effects were observed by Zamorano et al. ${ }^{4)}$ for Blatella germanica, Lygaeus militaris, and Pyrrhocoris apterus. Treatment with $\mathbf{2}$ can produce sterility in ticks such as Ornitodorus parkeri ${ }^{5}$ ) and Rhipicephalus sanguineus. ${ }^{6}$ )

Saxena et al. ${ }^{7)}$ found beta-asarone (20) isolated from the sweet flag (Acorus calamus) to cause sterility without producing precocious metamorphosis.

Matolcsy et al. ${ }^{8,9)}$ synthesized 1,2-dimethoxy-5-isopropoxy-4-vinylbenzene (7) by the hybridization of beta-asarone (20) and $\mathbf{2}$. Coumpound 7 is a precocene derivative with an open pyrane ring. This compound caused both precocious metamorphosis and a de-

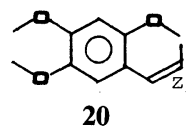

crease in egg production by $D$. cingulatus.

In this paper we describe the synthesis and the sterilizing and toxic activities of other 5isopropoxy-4-vinylbenzenes $(\mathbf{4} \sim \mathbf{8})$ and of alkoxybenzenes without double bond. Scale insects, which are seldom used in insect antihormone studies, were the test organisms.

The citrus mealybug (Planococcus citri Risso) is a major pest of citrus nd other crops. Several other species of mealybugs that infect foliage and roots are also difficult to control on many field- and greenhouse crops.

The functions of natural juvenile hormones and juvenoids in the reproduction of scale insects are well known. After treatment of the first instar larvae of $P$. citri with kinoprene, methoprene, or hydroprene, numbers of progeny decreased significantly. ${ }^{10)}$ These insect usually initiate ovisac formation but eggs are not deposited there. ${ }^{11)}$ In this case, histological observation of the ovarium showed decreased numbers of trophocytes, which have degenerated. Thus, the development of oocytes is 


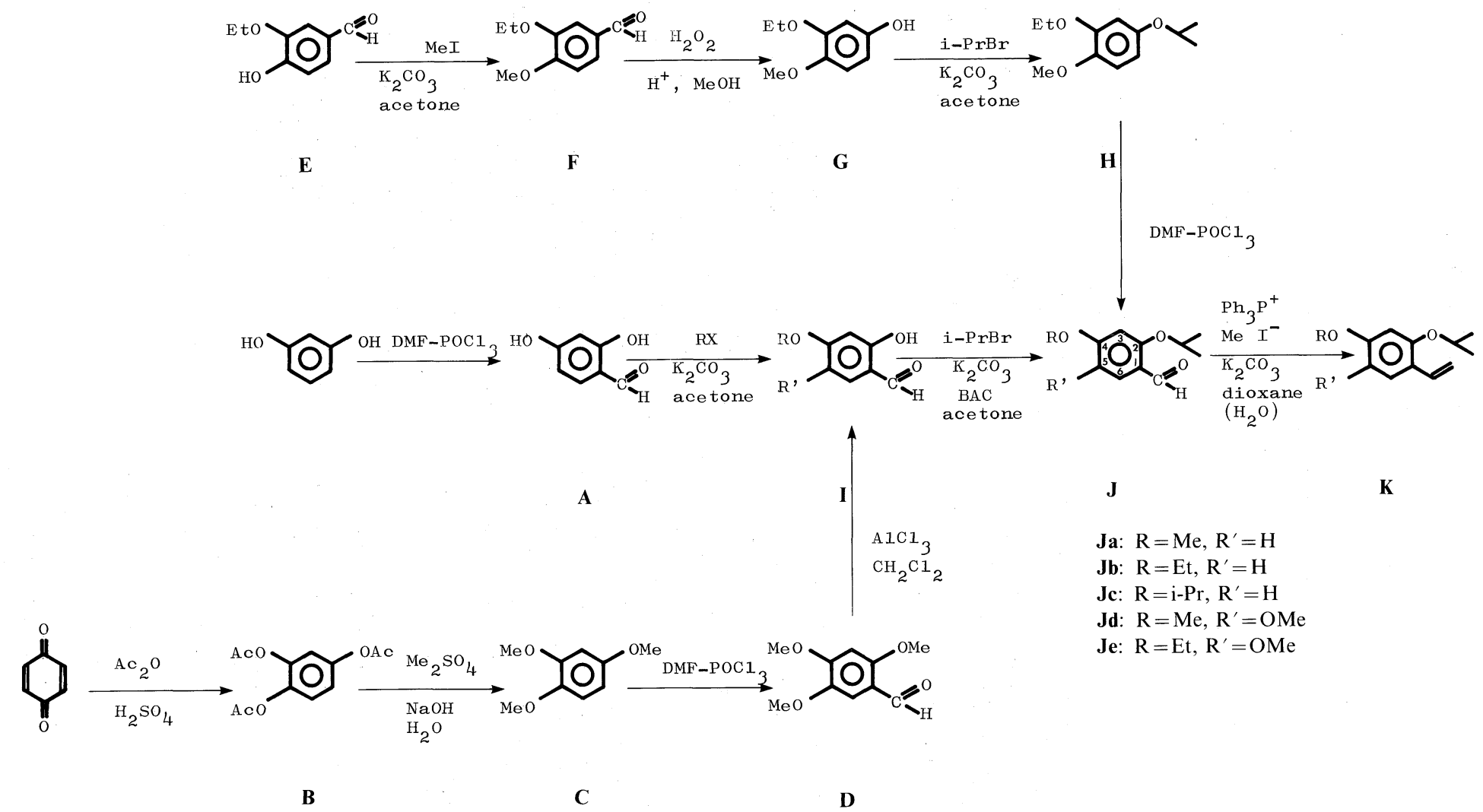

FIG. 1. General Scheme for Preparation of Alkoxybenzenes and Alkoxyvinylbenzenes. 
completely inhibited. ${ }^{12)}$ After treatment of adults, the wax glands that secrete the ovisac cease to function and, as a consequence, the females lay eggs only in a single row and without any protective secretion. ${ }^{12}$ )

The effects of insect-growth regulators on scale insects were summarized by Darvas and Varjas. $^{13)}$

\section{MATERIALS AND METHODS}

Synthesis. The original procedure for the synthesis of alkoxyvinylbenzene derivatives was based on reduction of the appropriate acetophenone to the corresponding alcohol, the dehydration of which was expected to yield the vinylbenzene derivative (K). ${ }^{9}$ 'This synthetic route was, however, not suitable because the dehydration gave very poor yields $(5 \sim 7 \%)$. Other authors ${ }^{14)}$ have also reported failure in the dehydration of similar compounds, so we chose other ways (Fig. 1) to synthesize the derivatives.

For derivatives of 1-alkoxy-5-isopropoxy-4-vinylbenzene $(\mathbf{4} \sim 6, \quad \mathrm{R}=\mathrm{H})$, we started from 2,4-dihydroxybenzene-1-carboaldehyde (A). The $\mathrm{OH}$ group in the ortho position froms a chelate ring and is hindered by the aldehyde group, so $\mathbf{A}$ can be selectively alkylated to afford 4-alkoxy-2-hydrobenzene-1-carboaldehyde (I, $\left.\mathbf{R}^{\prime}=\mathbf{H}\right)$. The isopropylation of $\mathbf{I}$ in the ortho position was not as easy as with the usual phenols owing to the difficulties described above.

We have tried a number of methods including sodium ethoxide in ethanol, potassium carbonate in acetone and in dimethylformamide (DMF), and liquid-liquid phase transfer systems using different catalysts, but none of them gave good yield. The solid-liquid phase-transfer system was the best. This method, giving an $80 \%$ yield, uses benzyltributylammonium chloride (BAC) as the phasetransfer catalyst, potassium carbonate as the acid acceptor, and acetone as solvent. Other phase-transfer catalysts, triethylbenzylammonium chloride, methyltrialkyl- $\left(\mathrm{C}_{8}-\right.$ $\mathrm{C}_{10}$ )-ammonium chloride (Adogen 464), and cetylpyridinium bromide, were tried but BAC was most effective.

The double bond of alkoxyvinylbenzene (K) was formed by a simplified Witting-Horner reaction in different media ${ }^{15)}$ by a solid-liquid transfer process. The corresponding aldehydes $(\mathbf{J})$ were reacted with methyltriphenylphosphonium iodide in the presence of potassium carbonate in dioxane that contained a small amount of water.

Biological tests. Citrus mealybugs were maintained on etiolated potato sprouts in ventilated plastic boxes in an environment of $30^{\circ} \mathrm{C}, 60 \sim 80 \%$ relative humidity, and a cycle of $16 \mathrm{hr}$ light, $8 \mathrm{~h}$ dark. The test compounds were diluted in acetone and sprayed onto the sprots and tubers with a "Rofra" sprayer until drops ran off. To evaluate the toxicity of the compounds, 120 to 200 first-instar larvae were placed onto a potato tuber in a plastic box. Twentythree days later, the survivors were counted and the toxicity in terms of the percentage of larvae killed was calculated by the Henderson-Tilton formula. We expected fecundity to be affected after day 28 when the treated larvae became adults. Fecundity was measured by examining the ovisacs of 10 females for each treatment. In statistical treatment of the data (one way ANOVA), the lowest two values for egg production were discarded. Some female mealybugs lay eggs late, so the variation arising from difference in individual developmental time could be reduced by discarding extremes in data. Females much smaller than the acetone-treated controls were prepared by Wilkey's method ${ }^{16)}$ for microscopic examination, where body length was measured several different ways and the morphology of the antennae examined.

\section{RESULTS AND DISCUSSION}

Results are summarized in Table 1.

Precocenes $1 \sim 3$ were only moderately toxic at the concentration of $0.1 \%$. The alkoxyvinylbenzene derivatives $(\mathbf{4} \sim \mathbf{8})$ were more toxic. The vinylbenzenes with three alkoxy groups (7 8) were less toxic than those with two $(4 \sim 6)$. At $0.05 \%$ the toxicity of $4 \sim 6$ was lost. The alkoxybenzene derivatives without the double bond present in the precocenes and the vinylbenzenes were not toxic. The compounds without an isopropyl group in the meta position to another alkoxy group were moderately toxic except for 1,2,5-trimethoxybenzene (11), which was not at all toxic.

Of the surviving adults, many were males.

Of all the compounds examined for their sterilizing action only 1,5-diisopropyl-4vinylbenzene (6) was effective. It reduced egg production by $70 \%$ compared with the untreated control. Dialkoxyvinylbenzenes 4, 5 , and $\mathbf{6}$ also decreased the number of eggs laid by the females; the chemosterilizing activity of the trialkoxy derivatives $\mathbf{7} \sim \mathbf{8}$ was not great.

Precocenes 1 and 3 reduced egg production somewhat, but $\mathbf{2}$ hardly of all.

The females treated with $0.1 \% 6$ were strongly retarded in their growth. Their mean body length $(1.35 \pm 0.12)$ was only $56 \%$ of the length of the controls $(2.43 \pm 0.24 ; p<0.01)$. The antennae of the insects had features char- 
Table I. Toxic and Chemosterilizing Activity of Precocenes, Alkoxybenzenes and ALKOXYVINYLBENZENES ON $P$. citri

\begin{tabular}{|c|c|c|c|c|c|}
\hline \multirow{3}{*}{ No. } & \multirow{3}{*}{ Structure } & \multicolumn{4}{|c|}{ Concentration } \\
\hline & & \multicolumn{2}{|r|}{$0.1 \%$} & \multicolumn{2}{|r|}{$0.05 \%$} \\
\hline & & $\begin{array}{l}\text { Toxicity } \\
(\%)\end{array}$ & $\begin{array}{c}\text { Mean No. of } \\
\text { eggs/female } \pm S E^{b}\end{array}$ & $\begin{array}{l}\text { Toxicity }^{a} \\
(\%)\end{array}$ & $\begin{array}{c}\text { Mean No. of } \\
\text { eggs/female } \pm \mathrm{SE}^{b}\end{array}$ \\
\hline $1(\mathrm{P} 1)$ & & 12 & $131.5 \pm 40.5 \mathrm{BC}$ & - & - \\
\hline $2(\mathrm{P} 2)$ & & 49 & $205.8 \pm 88.1 \mathrm{AB}$ & - & - \\
\hline $3(\mathrm{P} 3)$ & & 34 & $145.9 \pm 15.2 \mathrm{~B}$ & - & - \\
\hline 4 & & 84 & $124.3 \pm 31.2 \mathrm{BC}$ & 9 & $126.1 \pm 17.2 \mathrm{Y}$ \\
\hline 5 & & 70 & $143.5 \pm 17.8 \mathrm{~B}$ & 0 & $160.0 \pm 28.0 \mathrm{XY}$ \\
\hline 6 & & 83 & $75.0 \pm 10.1 \mathrm{C}^{c}$ & 6 & $131.0 \pm 40.0 \mathrm{Y}$ \\
\hline 7 & & 53 & $190.5 \pm 42.4 \mathrm{AB}$ & - & - \\
\hline 8 & & 65 & $204.9 \pm 37.2 \mathrm{AB}$ & - & - \\
\hline 9 & & 0 & $192.1 \pm 58.6 \mathrm{AB}$ & - & - \\
\hline 10 & & 39 & $201.5 \pm 47.8 \mathrm{AB}$ & - & - \\
\hline 11 & & 0 & $251.9 \pm 22.7 \mathrm{~A}$ & - & - \\
\hline 12 & & 35 & $230.3 \pm 36.5 \mathrm{~A}$ & - & - \\
\hline 13 & & 44 & $166.1 \pm 34.5 \mathrm{~B}$ & - & - \\
\hline 14 & & 0 & $202.5 \pm 70.3 \mathrm{AB}$ & - & - \\
\hline 15 & & 0 & $207.6 \pm 53.9 \mathrm{~A}$ & - & - \\
\hline 16 & & 0 & $208.0 \pm 43.8 \mathrm{AB}$ & - & - \\
\hline 17 & & 17 & $198.3 \pm 35.4 \mathrm{AB}$ & - & - \\
\hline
\end{tabular}


TABLE I. (continued).

\begin{tabular}{l} 
Concentration \\
\cline { 3 - 4 }
\end{tabular}

acteristic of adults, but the females did not form an ovisac and did not lay eggs within one week, the usual time for normal adults.

Neither of the compounds tested altered the secretion by wax glands.

Compounds 5 and $\mathbf{6}$ can be thought of as precocene derivatives the pyrane ring of which is opened; their mechanism of action may be similar to that of precocenes. However, the dialkoxy- and trialkoxybenzenes that lack the characteristic double bond needed for precocene activity are not representatives of precocenes.

Mealybugs (Pseudococcidae) are the oldest family of scale insects, a connecting link between the aphids and other families of scale insects. ${ }^{17)}$ The biological effects of precocenes have certain parallels between scale insects and their distant relatives, the aleyrodids and aphids. None of the precocenes $(\mathbf{1} \sim \mathbf{3})$ were very toxic for the aphids Acyrthosiphon pisum and Myzus persicae or for aleyrodids aleyrodes brassicae and Trialeurodes vaporariorum. ${ }^{18)}$ Treatment of $A$. pisum $^{19)}$ and Macrosiphum euphorbiae ${ }^{20)}$ with 2 increased the numbers of alate forms. The same treatment of $M$. persicae increased the proportions of males ${ }^{21)}$ and of oviparous-viviparous adultoids. ${ }^{22)}$

In our experiments, the toxicity of precocenes for $P$. citri was moderate, similar to that found for aphids and aleyrodids. The effects on the sexes was not different unlike juvenoids, which decrease the proportion of males. ${ }^{12)}$ These findings suggest that $P$. citri has a physiologically level of juvenile hormone different for the sexes. Males reacted to the rise in the level of juvenile hormone more than females; while females tolerated some decrease.

Another family of scale insects, the armored scale insects (Diaspididae), are much more sensitive to precocenes than mealybugs. When $0.1 \% 2$ was used to treat the first instar larvae of Quadraspidiotus perniciosus, the insects died, and even on the 4th day after treatment, half of the animals did not survive on the treated surface. ${ }^{23)}$

Precocenes are highly cytotoxic to the corpora allata, and cause the destruction of the gland responsible for production of juvenile 
hormone. Precocenes themselves are proallatocidins, and their action probably arises from activation mediately cytochrome P-450. A highly reactive 3,4-epoxy-derivative is formed, which reacts with nucleophilic substrates in the gland, leading to the death of the corpora allata. $^{24 \sim 26)}$

The precocene-like activity of 7, 1,2dimethoxy-5-isopropoxy-4-vinylbenzene, on D. cingulatus causes morphogenetical alteration, so such activity is not restricted to compounds with a chromene ring structure, but a double bond is an absolute requirement. ${ }^{8)}$ Compounds $\mathbf{4} \sim \mathbf{8}$ did not affect the morphology of $P$. citri, but their toxic and sterilizing activities surpasses those of precocenes.

The presence of a double bond in a xenobiotic always provides a possibility for the organism to eliminate the chemical by an oxidative process via different oxygenases. Oxidative bioactivation of the double bond is probably involved in the mechanisms of $\mathbf{4} \sim \mathbf{8}$. many structures with a terminal $\pi$-bond inactivate cytochrome P-450 by alkylating its prostetic heme group by the oxydation of a double bond. ${ }^{27)}$ This probability seems likely because alkoxybenzenes without a vinyl group are inactive; the only exception is 19 , but the methylenedioxy structure is also an inhibitor of cytochrome P-450.

The biological action of $\mathbf{4} \sim \mathbf{8}$ surpassing that of precocenes provides a new theoretical base for the development of novel insectgrowth regulators.

\section{EXPERIMENTAL}

IR spectra were recorded with a Bruker IFS-113-VFI IR spectrometer. NMR spectra were made with a Bruker WM-250 FT spectrometer using 2,3,5,6-tetramethyl- $p$ xylene- $\alpha, \alpha^{\prime}$-diol as an internal standard. Melting points are uncorrected. The results of elemental analysis found were in agreement with those calculated (within $0.3 \%$ error).

Compounds $\mathbf{A}$ and $\mathbf{D}$ were prepared with a Vilsmeyer formulation of resorcinol and 1,3,6-trimethoxybenzene (C), respectively, as described elsewhere. ${ }^{28,29)}$ Compound C was synthesized by the simultaneous hydrolysis and methylation of 1,3,6-triacetoxybenzene ${ }^{29)}$ obtained from benzoquinone. ${ }^{30)}$ The selective alkylations of the hydroxy group in the 3 position of $\mathbf{A}$ were done with the corresponding alkyl bromide or iodide in acetone in the presence of $\mathrm{K}_{2} \mathrm{CO}_{3}$. Alkoxybenzenes 9 10 and 12 19 were synthesized from the appropriate phenols with the same alkylation method. We used procedure described elsewhere $^{31)}$ for the acid-catalyzed oxidation of benzaldehydes with hydrogen peroxide to phenols for the preparation of $\mathbf{G}$. The selective ortho demethylation of $\mathbf{D}$ was done with $\mathrm{AlCl}_{3}$ in $\mathrm{CH}_{2} \mathrm{Cl}_{2}$ as described elsewhere. ${ }^{32}$ )

In the general procedure for the preparation of 4,5dialkoxy-2-isopropoxybenzene-1-carboaldehyde (J), mixture of 2-hydroxybenzaldehide derivative (I) $(20 \mathrm{mmol})$, isopropyl bromide $(9.84 \mathrm{~g}, 80 \mathrm{mmol})$, anhydrous $\mathrm{K}_{2} \mathrm{CO}_{3}(5.52 \mathrm{~g}, 40 \mathrm{mmol})$, and benzyltributylammonium chloride $(1.9 \mathrm{~g}, 6 \mathrm{mmol})$ in $30 \mathrm{ml}$ of dry acetone was refluxed and stirred for $5 \sim 6$ hours. When the reaction (followed by TLC) ended, the mixture was no longer yellowish. Inorganic salts were filtered off by suction, and washed with acetone. The acetone solution was evaporated under reduced pressure. Ether and water were added to the remaining material, and the two phases were shaken and allowed to separate. The ether phase was washed with $5 \% \mathrm{NaOH}$ solution twice and with water. The resultant solution was treated with charcoal and dried over $\mathrm{Na}_{2} \mathrm{SO}_{4}$. after the ether was removed under reduced pressure, the product was distilled or recrystallized (if solid).

2-Isopropoxy-4-methoxybenzene-1-carboaldehyde (Ja). Yield: $83.9 \%$, bp $115 \sim 116^{\circ} \mathrm{C} / 0.8$ Torr, IR $(\mathrm{KBr})$ : $1675 \mathrm{~cm}^{-1}\left(v_{\mathrm{C}=\mathrm{o}}\right), \mathrm{H}$ NMR $\left(\mathrm{CDCl}_{3}\right): \delta: 1.40(6 \mathrm{H}, \mathrm{d}$, $J=8.0 \mathrm{~Hz}), 3.86(3 \mathrm{H}, \mathrm{s}), 4.64(1 \mathrm{H}, \mathrm{sp}), 6.32(1 \mathrm{H}, 2 \times \mathrm{d})$, $6.45(1 \mathrm{H}, \mathrm{d}, J=2.1 \mathrm{~Hz}), 7.80(1 \mathrm{H}, \mathrm{d}, 8.5 \mathrm{~Hz}), 10.31(1 \mathrm{H}, \mathrm{s})$.

4-Ethoxy-2-isopropoxybenzene-1-carboaldehyde (Jb). Yield: $83.1 \%$, bp $119 \sim 120^{\circ} \mathrm{C} / 0.3$ Torr, IR $(\mathrm{KBr})$ : $1670 \mathrm{~cm}^{-1}\left(v_{\mathrm{C}=\mathrm{O}}\right), \mathrm{H}$ NMR $\left(\mathrm{CDCl}_{3}\right): \delta ; 1.39(6 \mathrm{H}, \mathrm{d}$, $J=8 \mathrm{~Hz}), 1.43(3 \mathrm{H}, \mathrm{t}, J=7 \mathrm{~Hz}), 4.06(2 \mathrm{H}, \mathrm{qu}), 4.62(1 \mathrm{H}$, sp), $6.44(1 \mathrm{H}, \mathrm{d}, J=2.2 \mathrm{~Hz}), 6.60(1 \mathrm{H}, 2 \times \mathrm{d}), 7.78(1 \mathrm{H}, \mathrm{d}$, $J=8.7 \mathrm{~Hz}), 10.31(1 \mathrm{H}, \mathrm{s})$.

2,4-Diisopropoxybenzene-1-carboaldehyde (Jc). Yield: $81.3 \%$, bp $125 \sim 126^{\circ} \mathrm{C} / 0.4$ Torr, IR (film): $1675 \mathrm{~cm}^{-1}$ $\left(v_{\mathrm{C}=\mathrm{o}}\right), \mathrm{H}$ NMR $\left(\mathrm{CDCl}_{3}\right): \delta: 1.36(6 \mathrm{H}, \mathrm{d}, J=8 \mathrm{~Hz}), 1.39$ $(6 \mathrm{H}, \mathrm{d}, J=8 \mathrm{~Hz}), 2 \times 4.62(2 \times 1 \mathrm{H}, \mathrm{sp}), 6.47(1 \mathrm{H}, \mathrm{d}$, $J=1.6 \mathrm{~Hz}), 6.48(1 \mathrm{H}, 2 \times \mathrm{d}), 7.78(1 \mathrm{H}, \mathrm{d}, J=8.7 \mathrm{~Hz}), 10.30$ (1H, s).

4,5-Dimethoxy-2-isopropoxybenzene-1-carboaldehyde (Jd). Yield: $78.6^{\circ}, \mathrm{mp} .61 \sim 62^{\circ} \mathrm{C}$ (from hexane), IR $(\mathrm{KBr}): 1660 \mathrm{~cm}^{-1}\left(v_{\mathrm{C}=\mathrm{o}}\right), \mathrm{H} \mathrm{NMR}\left(\mathrm{CDCl}_{3}\right): \delta: 1.39(6 \mathrm{H}$, $\mathrm{d}, J=6.1 \mathrm{~Hz}), 3.88(3 \mathrm{H}, \mathrm{s}), 3.95(3 \mathrm{H}, \mathrm{s}), 4.4(1 \mathrm{H}, \mathrm{sp}), 6.52$ $(1 \mathrm{H}, \mathrm{s}), 7.30(1 \mathrm{H}, \mathrm{s}), 10.32(1 \mathrm{H}, \mathrm{s})$.

4-Ethoxy-2-isopropoxy-5-methoxybenzene-1carboaldehyde (Je). $\mathrm{POCl}_{3}(7.70 \mathrm{~g}, 37.2 \mathrm{mmol})$ was added dropwise to abs. DMF $(15 \mathrm{ml})$ and stirred with ice-water cooling at $5 \sim 10^{\circ}$.C. Then 1-ethoxy-3-isopropoxy-6methoxybenzene $(\mathbf{H})(6.3 \mathrm{~g}, 30 \mathrm{~mm})$ dissolved in abs. DMF $(15 \mathrm{ml})$ was added to this solution, and the stirring and cooling was continued. The mixture was then warmed at 
$40^{\circ} \mathrm{C}$ for two hours and poured into ice-water $(120 \mathrm{ml})$. The solution was made basic with $10 \% \mathrm{NaOH}$, and the precipitate was filtered off with suction, washed with water, and recrystallized from water-ethanol $(6: 4)$. Yield: $80.6 \%, \mathrm{mp}: 71 \sim 72 \mathrm{C}$, IR $(\mathrm{KBr}): 1664 \mathrm{~cm}^{-1}\left(v_{\mathrm{C}=\mathrm{O}}\right), \mathrm{H}$ NMR $\left(\mathrm{CDCl}_{3}\right): \delta: 1.38(6 \mathrm{H}, \mathrm{d}, J=6.1 \mathrm{~Hz}), 1.51(3 \mathrm{H}, \mathrm{t}$, $J=7 \mathrm{~Hz}), 3.87(3 \mathrm{H}, \mathrm{s}), 4.16(2 \mathrm{H}, \mathrm{qa}), .4 .57(1 \mathrm{H}, \mathrm{sp}), 6.51$ $(1 \mathrm{H}, \mathrm{s}), 7.30(1 \mathrm{H}, \mathrm{s}), 10.31(1 \mathrm{H}, \mathrm{s})$.

In the general method for the preparation of alkoxyvinylbenzenes $(\mathbf{K})$, mixture of the appropriate benzaldehyde (J) (5 mmol), methyltriphenylphosphonium iodide (4.04 g, $10 \mathrm{mmol})$, and finely powdered $\mathrm{K}_{2} \mathrm{CO}_{3}(1.38 \mathrm{~g}, 10 \mathrm{mmol})$ in peroxide-free dioxane $(5 \mathrm{ml})$ that contained $0.075 \mathrm{ml}$ of water was refluxed with vigorous stirring for $6 \sim 10$ hours. The reaction was monitored by TLC. The solids were filtered off with suction and washed with dioxane. The solvent was evaporated under reduced pressure, and the products obtained were purified by column chromatography. They were first put on a short column of silica gel in a small amount of dioxane and eluted with hexane only to remove triphenylphosphate oxide. Chromatography was then done on $200 \mathrm{ml}$ of gel using hexane-acetone $(10: 1)$ for elution.

1-Methoxy-5-isopropoxy-4-vinylbenzene (4). Yield: $68.3 \%$ IR (film): $1730 \mathrm{~cm}^{-1}\left(v_{\mathrm{C}=\mathrm{C}}\right), \mathrm{H} \mathrm{NMR}\left(\mathrm{CDCl}_{3}\right): \delta$ : $1.34(6 \mathrm{H}, \mathrm{d}, J=6 \mathrm{~Hz}), 3.80(3 \mathrm{H}, \mathrm{s}) 4.50(1 \mathrm{H}, \mathrm{sp}), 5.10(1 \mathrm{H}$, $2 \times \mathrm{d}), 5.62(1 \mathrm{H}, 2 \times \mathrm{d}), 6.45(\mathrm{Ar} 1 \mathrm{H}, \mathrm{d}), 6.48(\mathrm{Ar} 1 \mathrm{H}$, $2 \times \mathrm{d}), 6.80(1 \mathrm{H}, 2 \times \mathrm{d}, J=12.2$ and $17.2 \mathrm{~Hz}), 7.40($ Ar $1 \mathrm{H}$, d, $J=9 \mathrm{~Hz}$ ).

1-Ethoxy-5-isopropoxy-4-vinylbenzene (5). Yield: $63.5 \%$, IR (film): $1730 \mathrm{~cm}^{-1}\left(v_{\mathrm{C}=\mathrm{C}}\right), \mathrm{H} \mathrm{NMR}\left(\mathrm{CDCl}_{3}\right): \delta$ : $1.34(6 \mathrm{H}, \mathrm{d}, J=6.1 \mathrm{~Hz}), 1.40(3 \mathrm{H}, \mathrm{t}, J=7.1 \mathrm{~Hz}), 4.02(2 \mathrm{H}$, qa), $4.50(1 \mathrm{H}, \mathrm{sp}), 5.1(1 \mathrm{H}, 2 \times \mathrm{d}), 5.62(1 \mathrm{H}, 2 \times \mathrm{d}), 6.45$ (Ar $1 \mathrm{H} \mathrm{d}, J=2.1 \mathrm{hz}), 6.48($ Ar $1 \mathrm{H}, 2 \times \mathrm{d}), 6.96(1 \mathrm{H}, 2 \times \mathrm{d}$, $J=12.2$ and $17.1 \mathrm{~Hz}), 7.40(\operatorname{Ar} 1 \mathrm{H}, \mathrm{d}, J=9.0 \mathrm{~Hz})$.

1,5-Diisopropoxy-4-vinylbenzene (6). Yield: $61.6 \%$, IR (film): $1729 \mathrm{~cm}^{-1}\left(v_{\mathrm{C}=\mathrm{c}}\right), \mathrm{H} \mathrm{NMR}\left(\mathrm{CDCl}_{3}\right): \delta: 1.32(6 \mathrm{H}, \mathrm{d}$, $J=6.1 \mathrm{~Hz}), 1.34(6 \mathrm{H}, \mathrm{d}, J=6.1 \mathrm{~Hz}), 4.48(1 \mathrm{H}, \mathrm{sp}), 4.52$ $(1 \mathrm{H}, \mathrm{sp}), 5.1(1 \mathrm{H}, 2 \times \mathrm{d}), 5.62(1 \mathrm{H}, 2 \times \mathrm{d}), 6.42(\mathrm{Ar} 1 \mathrm{H}, \mathrm{d}$, $J=2.0 \mathrm{~Hz}), 6.46($ Ar $1 \mathrm{H}, 2 \times \mathrm{d}), 6.97(1 \mathrm{H}, 2 \times \mathrm{d}, J=12.2$ and $17.3 \mathrm{~Hz}), 7.40(\mathrm{Ar} 1 \mathrm{H}, \mathrm{d}, J=9.0 \mathrm{~Hz})$.

1,2-Dimethoxy-5-isopropoxy-4-vinylbenzene (7). Yield: $58.9 \%$, IR (film): $1728 \mathrm{~cm}^{-1}\left(v_{\mathrm{C}=\mathrm{C}}\right), \mathrm{H} \mathrm{NMR}\left(\mathrm{CDCl}_{3}\right): \alpha$ : $1.35(6 \mathrm{H}, \mathrm{d}, J=6.2 \mathrm{~Hz}), 3.85(3 \mathrm{H}, \mathrm{s}), 3.88(3 \mathrm{H}, \mathrm{s}), 5.00$ $(1 \mathrm{H}, 2 \times \mathrm{d}), 5.21(1 \mathrm{H}, 2 \times \mathrm{d}), 6.45(1 \mathrm{H}, \mathrm{s}), 6.82(1 \mathrm{H}, 2 \times \mathrm{d}$, $J=11.9$ and $17.3 \mathrm{~Hz}), 7.08(1 \mathrm{H}, \mathrm{s})$.

1-Ethoxy-5-isopropoxy-2-methoxy-4-vinylbenzene (8). Yield: $57.9 \%$, IR (film): $1726 \mathrm{~cm}^{-1}\left(v_{\mathrm{C}=\mathrm{C}}\right), \mathrm{H}$ NMR $\left(\mathrm{CDCl}_{3}\right): \delta: 1.31 \quad(6 \mathrm{H}, \mathrm{d}, \quad J=6.3 \mathrm{~Hz}), 1.45 \quad(3 \mathrm{H}, \mathrm{t}$, $J=7.1 \mathrm{~Hz}), 3.86(3 \mathrm{H}, \mathrm{s}), 4.07(2 \mathrm{H}, \mathrm{qa}), 4.35(1 \mathrm{H}, \mathrm{sp}), 5.13$ $(1 \mathrm{H}, 2 \times \mathrm{d}), 6.51(1 \mathrm{H}, \mathrm{s}), 7.00(1 \mathrm{H}, 2 \times \mathrm{d}, J=1.40$ and $11.2 \mathrm{~Hz}), 7.01(1 \mathrm{H}, \mathrm{s})$.

Acknowledgments. This study was done as part of the project HUN/82/006 sponsored by the UNDP/ UNIDO/FAO and named "Strengthening research on non-toxic insecticides". We gratefully acknowledge financial and organizational support from these organizations. We thank Professor P. Sohár for interpretation of the IR and NMR spectra and Mrs. I. Laczay and Miss K. Eröss for technical assistance.

\section{REFERENCES}

1) A. R. Alertsen, Mill. Acta Polytech. Scand., Ser. B, 10, 1 (1961).

2) W. S. Bowers, “The Juvenile Hormones," ed. by L. I. Gilbert, Plenum Press, New York, 1976, pp. $394 \sim 408$.

3) W. S. Bowers, T. Ohta, J. S. Cleere and P. A. Marsella, Science, 193, 542 (1976).

4) M. D. G. Zamorano, C. T. Martinez, A. L. Enquix, R. M. Pardo and A. C. Cachaza, "Juvenile Hormone Biochemistry," ed. by G. E. Pratt and G. T. Brooks, Elsevier, North-Holland Biomedical Press, Amsterdam, 1981, pp. $311 \sim 314$.

5) J. M. Pound and J. H. Oliver, Science, 206, 355 (1979).

6) M. G. Leahy and K. S. Booth, J. Med. Entomol., 17, 18 (1980).

7) B. P. Saxena, O. Koul, K. Tikku and C. K. Atal, Nature, 270, 512 (1977).

8) G. Matolcsy, Y. M. Darwish, I. Bélai, L. Varjas and A. I. Farag, Z. Naturforsch., 35b, 1449 (1980).

9) G. Matolcsy, A. I. Farag, L. Varjas, I. Bélai and Y. M. Darwish, "Juvenile Hormone Biochemistry," ed. by G. E. Pratt and G. T. Brooks, Elsevier, NorthHolland Biomedical Press, Amsterdam, 1981, pp. $393 \sim 413$.

10) G. B. Staal, S. Nassar and J. W Martin, J. Econ. Entomol., 66, 851 (1973).

11) E. Jászai-Virág and B. Darvas, Proc. Int. Conf. Integr. Plant Prot., ed. by B. Darvas, M. Tóth and L. Vajna, Vol. 4, Kertészeti Egyetem Nyomda, Budapest, 1983, pp. 198 202 .

12) B. Darvas, Növényvédelem, in press.

13) B. Darvas and L. Varjas, "Diaspididae," ed. by D. Rosen, Elsevier, Amsterdam, in press.

14) F. Bohlmann and F.-M. Stofr, Liebigs Ann. Chem., 185, 191 (1980).

15) Y. Le Bigot, M. Delmas and A. Gaset, Synth. Commun., 12, 107 (1982).

16) J. O. Howel and M. Kosztarab, Res. Div. Bull., 70(4), 6 (1972).

17) Ju. A. Popov, "Istoritcheskoje Razviti Klassa Nasekomih," ed. by B. B. Rodendorf and I. I. Rasnicin, Izdatelvo "Nauka," Moskow, 1980, pp. $59 \sim 69$.

18) B. Darvas, L. Varjas, P. Kulcsár, T. Timár and S. Hosztafi, Pest. Science, in press.

19) M. MacKauer, K. K. Nair and G. C. Unithan, Can. J. Zool., 57, 856 (1979).

20) J. Delisle, C. Cloutier and J. N. McNeil, J. Insect Physiol., 29, 477 (1983). 
21) D. F. Hales and T. E. Mittler, J. Insect Physiol., 29, 819 (1983).

22) D. F. Hales and T. E. Mittler, J. Insect Physiol., 27, 333 (1981).

23) B. Darvas, A. I. Farag, F. Kozár and E. T. E. Darwish, Acta Phytopath. Acad. Sci. Hung., 20, 86 (1985).

24) G. T. Brooks, G. E. Pratt and R. C. Jennings, Nature, 281, 570 (1979).

25) G. E. Pratt, R. C. Jennings, A. F. Hamnett and G. T. Brooks, Nature, 284, 320 (1980).

26) R. Feyereisen, G. E. Pratt and A. F. Hamnett, Eur. J. Biochem., 118, 231 (1981).
27) P. R. Ortiz de Montellano and M. A. Correia, Ann. Rev. Pharmacol., 23, 481 (1983).

28) M. Bisagni, Ng Buu Hoi and R. Royer, J. Chem. Soc., 1955, 3693.

29) J. J. Birch, J. H. Jackson, P. V. R. Shannon and G. W. Stewart, J. Chem. Soc., Perkin Trans. 1, 1975, 2492.

30) "Org. Synth. Coll.," Vol. 3, 829, John Wiley Inc., New York, 1967.

31) M. Matsumoto, H. Kobayashi and Y. Hotta, J. Org. Chem., 49, 4740 (1984).

32) R. S. Mali, V. J. Yadav and R. N. Zaware, Ind. J. Chem., 21B, 759 (1982). 